\title{
BMJ Open Personal-recovery-oriented community mental healthcare: qualitative evaluation of a developmental project
}

\author{
Thijs Beckers (D) , ${ }^{1,2}$ Lia Jaeqx - van Tienen, ${ }^{2}$ Rudy Willems, ${ }^{2}$ Martijn Koopmans, ${ }^{2}$ \\ Dirk Corstens ${ }^{2}$
}

To cite: Beckers T, Jaeqx - van Tienen L, Willems $R$, et al. Personal-recoveryoriented community mental healthcare: qualitative evaluation of a developmental project. BMJ Open 2020;10:e035709. doi:10.1136/ bmjopen-2019-035709

- Prepublication history for this paper is available online. To view these files, please visit the journal online (http://dx.doi. org/10.1136/bmjopen-2019035709)

Received 12 November 2019

Revised 08 May 2020

Accepted 11 May 2020
Check for updates

(c) Author(s) (or their employer(s)) 2020. Re-use permitted under CC BY-NC. No commercial re-use. See rights and permissions. Published by BMJ.

${ }^{1}$ Research Group Social Psychiatry and Mental Health Nursing, Hogeschool Arnhem Nijmegen University of Applied Science, Schinveld, The Netherlands

${ }^{2}$ MET ggz, Roermond, Limburg, The Netherlands

Correspondence to

Thiijs Beckers;

thijsbeckers@me.com

\section{ABSTRACT}

Objectives Mental healthcare is commonly aimed at reducing symptoms in individual service users. When only symptomatic recovery is addressed, not all service users experience sufficient recovery, and when care is aimed only at individuals (instead of the neighbourhood), not all people in need of mental healthcare are reached. This study evaluated a project that aimed to improve mental healthcare in a neighbourhood, by improving healthcare providers' outreach to the residents living in the neighbourhood, by improving collaboration among healthcare providers and focussing on the residents' personal recovery. This project was carried out by several public health services. It aimed to change the goal of mental healthcare provided in the neighbourhood from symptom reduction to personal recovery.

Design The study included qualitative focus groups and inductive content analysis.

Setting Primary and secondary mental healthcare that healthcare workers from different healthcare services provided.

Participants The evaluation was conducted through three focus group interviews with services users, their friends and relatives, neighbourhood residents, neighbourhood representatives and the healthcare services that were involved $(n=24)$.

Results Evaluation indicated that the most valued part of the project was the utilisation of peer workers at the initiation of mental healthcare. Improved communication among healthcare providers that the project fostered was also highly regarded. The aim of the project to align it with existing initiatives in the neighbourhood was also considered important, although it was difficult to achieve. Conclusions The project did not find a panacea for recovery-oriented community mental healthcare. A variety of its components did, however, contribute to the mental health of the community residents.

\section{INTRODUCTION}

Mental healthcare is generally of high quality in the Netherlands. There are, nevertheless, considerable challenges for achieving a mental healthcare system that is available for everyone in need of this care and which is sustainable in the future. ${ }^{1-3}$ Access to mental healthcare is hindered mostly by stigma and mental-health illiteracy. ${ }^{4-7}$ Other factors

\section{Strengths and limitations of this study}

Analysis with independent coding by two researchers.

- Sufficient sample size ( $n=24)$ for a qualitative study.

- Data saturation achieved in the third focus group interview.

- Limited generalisability due to sampling within one project in one neighbourhood.

like poverty, specific needs due to ethnicity, language difficulties and other sociodemographic variables also heighten the barrier to seeking help from mental-health services. $^{8}{ }^{9}$ Improving the accessibility of mental healthcare is even more difficult than increasing capacity or funding. Instead, the factors that make seeking mental healthcare difficult, especially the stigma and mentalhealth illiteracy, ${ }^{10-13}$ should be addressed,.

The cost of mental healthcare is also a concern in the Netherlands, as it is in most countries. Because the funds provided for mental healthcare are largely capped, the amount of care that is available is fixed. ${ }^{14}{ }^{15}$ Thus, the available care must be divided among all people with a need for mental healthcare. ${ }^{16-19}$

Another current issue in mental healthcare is the shift away from aiming to achieve symptomatic and functional recovery to achieving personal recovery. Symptomatic recovery is focussed on relieving the symptoms of a mental illness, whereas functional recovery is aimed at improving the functioning of the service user in society (for example, in work or social support). Advocates of personal recovery state, however, that there is more to recovery than relieving symptoms and improving functioning. Personal recovery is about the individual's interpretation of the mental illness, the cause of the mental illness and the effects of the mental illness on how the person's life is turning out. In 
other words, personal recovery takes the perspective that people who experience a mental illness not only want to reduce their complaints and improve their functioning in society; they also need to come to terms with their mental illness and how it affects their life. ${ }^{20}$ As described by the CHIME-D framework, the main components of personal recovery are connectedness, hope and optimism about the future, identity, meaning in life and empowerment for overcoming difficulties, for example, financial problems or a mental illness. ${ }^{21} 22$

In order to increase the sustainability of mental healthcare in the Netherlands, a project called Recovery Focused Community Mental Healthcare (RFCMH) was started in one underprivileged neighbourhood in a rural city. The aim of RFCMH is to improve the mental health of the residents living in the neighbourhood in a sustainable manner. The RFCMH project is based on the concepts that van Os $e t a l^{23}$ described. These concepts can be summarised as a plea to replace the common view and approach to mental healthcare that is based on 'specialist practitioners who apply evidence-based guidelines of symptom reduction aimed at the group level'. ${ }^{23}$ Instead, a model is proposed that is based on personal recovery, 'fostering connectedness and strengthening resilience in learning to live with mental vulnerability, complemented by a limited number of regional facilities'. ${ }^{23}$

The project was intended to test the main principles of RFCMH and to further develop RFCMH into a model that can be generalised to other neighbourhoods and other cities. RFCMH is a joint venture of multiple groups who are concerned with mental healthcare. They include social workers, welfare organisations, general practitioners, health insurance companies, those who care for people with learning difficulties and the municipality. At this stage in its development, RFCMH has four guiding principles: (a) a focus on personal recovery, (b) utilising peer workers as the default healthcare practitioners who liaison with others to organise further care, if it is needed, (c) investing in lowering the threshold for mental healthcare for community residents and (d) lowering the threshold for healthcare providers to collaborate with one another.

The study discussed in this paper was aimed at the mental well-being of the residents living in the neighbourhood under study after RFCMH had been implemented. The overarching hypothesis was that the following factors would lead to improved mental healthcare for the community: better alignment of healthcare providers with the personal circumstances of the residents, better use of the social infrastructure of the community, improved access to social support and improved access to mental healthcare. In short, the research question that we addressed was: What is the perceived contribution of RFCMH to the mental health of the residents living in the targeted neighbourhood?

\section{MATERIALS AND METHODS}

This study was designed as an exploratory qualitative study using focus group interviews and thematic content analysis. The study is reported in accordance with the Standards for Reporting Qualitative Research guideline. ${ }^{24}$

\section{The neighbourhood}

The neighbourhood where the project was conducted is located in a rural city in the Netherlands. It had 7121 residents at the start of the project. ${ }^{25}$ The neighbourhood is considered multilingual and multicultural; around $60 \%$ of the residents have a migration background. ${ }^{25}$ Among the adults in the neighbourhood, $50.7 \%$ had a job, and $21.6 \%$ were retired, $27.7 \%$ were unemployed or not able to work due to disability. The unemployment and disability rate is higher than average in the Netherlands. ${ }^{25}$ Around $20 \%$ of the residents had the minimum legal income or less; the average income of residents in the neighbourhood was $73 \%$ of the average income in the Netherlands. ${ }^{26}$ Of the residents, $19 \%$ were 15 years old or younger, $66 \%$ were between 15 and 65 years old and $15 \%$ were older than 66 years.$^{25}$ Compared with the rest of the region and the Netherlands as a whole, the residents were younger than average. ${ }^{26}$

\section{The project}

At the start of the project, it was difficult to discuss the focus, goals and approach of the project with the services that were involved. All of the services were convinced that the RFCMH had merit, but they had divergent views about the perspectives on the approach, the division of the tasks and the alignment of the project with existing policies and laws. Thus, it was not possible to achieve a project plan that all of the involved services supported. Instead, all of the participants agreed to start without a specific project plan and to make the necessary choices along the way. An example of one of these choices that needed to be made was how different healthcare providers would collaborate with one another in helping residents with mental health issues. The decision to make choices along the way was a useful development because it caused the project to be focussed on daily practice instead of on theoretical issues. Residents living in the neighbourhood, peer workers and patient representatives were involved in these discussions, and thus these people had a considerable impact on the focus of the project.

As discussed in the Introduction, RFCMH had four guiding principles when the study was conducted. All these principles had been implemented 1 year before data collection began. The first principle was to focus on personal recovery. This focus was important because improving personal recovery increases a person's quality of life and decreases the need for care. ${ }^{21}{ }^{27}$ Implementation of care that was oriented towards personal recovery was achieved by (a) changing the focus of the care to interventions that were more aimed at improving personal recovery and (b) enhancing the knowledge of the healthcare providers who were involved about personal 
recovery, so that they could help service users achieve their personal goals. An example of changing the focus to personal recovery is that of a woman who was referred by her general practitioner for a major depressive disorder. During the first two conversations with a peer worker, it became clear that this woman did not feel safe in her own house and that she also felt lonely. Thus, the focus of the help she received was on finding a more suitable place for her to live. When this service user moved to a new house (procured with the help of a peer worker), her symptoms of the depression subsided.

The second guiding principle was to use peer workers as the default healthcare practitioners and as the liaison in organising further care, in case it was needed. All of the peer workers who were involved with the project had received formal training, usually in a 4-year course. This course is a common educational programme for peer workers in the Netherlands. It includes general elements of the educational programme for social workers as well as specific elements for peer workers to be able to use their own experiences in a structured and thoughtful way when working with service users. The peer workers were employed by a mental health service. Using peer workers ensured that the focus would be on the service users' personal recovery, and it strengthened the alliance between the peer workers and the healthcare providers by assigning the peer workers to a key role. ${ }^{28}$ Allowing the peer workers to be primary healthcare practitioners meant that, unless there was a clear need for a healthcare provider, the first session with the service user would be with a peer worker. If possible, future sessions would also be with the peer worker. If care by a healthcare provider (eg, a mental-health nurse, psychologist or psychiatrist) were needed, the peer worker would liaise with an appropriate healthcare provider to arrange a session as soon as possible.

The third guiding principal was to invest in outreach, both to the residents and to other healthcare providers in the neighbourhood. One of the aims of the RFCMH was to lower the threshold for mental healthcare for the residents in need for care. An effective way of doing so would be to reach out to residents who might need mental healthcare, instead of waiting for these residents to ask for help themselves. ${ }^{29} 30$ The outreach was achieved by assigning the healthcare providers involved in RFCMH (especially the peer workers) the task of frequently visiting places where people who needed mental healthcare would likely be (eg, general practitioners' offices, neighbourhood meeting places, the welfare centre). When visiting one of these places, the peer workers would engage the visitors at these places in a conversation about mental health and would assist them in asking for help when it was needed.

The fourth and final guiding principle was to improve the collaboration among the healthcare providers. If all of the healthcare providers who were or should be involved with a specific service user cooperated effectively, this would benefit all of the people involved. Service users would receive integrated care, and healthcare providers would have to put forth less effort in order to achieve the service user's goals. ${ }^{31-33}$ Improving the cooperation among all of healthcare providers who were involved in a service user's care was achieved by building a network of healthcare providers in order to develop and use new ways of improving the mental health of the residents of the community. All of the healthcare providers who were involved contributed their knowledge and efforts to the collaboration. This collaboration consisted of three main activities. First, a weekly 1-hour meeting was organised for all of the healthcare providers who were working within the neighbourhood. During these meetings, both individual service users' issues (for example, which healthcare provider was best suited to care for a specific service user) and more general issues (for example, new resources in the neighbourhood for sharing knowledge) could be discussed. Second, each month a peer worker and a psychiatrist visited each general practitioner in the neighbourhood. The purpose of these visits was to discuss individual service users and the care they were receiving or would need, but on several occasions more general problems in the neighbourhood were discussed. Third, several meetings were organised with residents in the community to discuss mental-health issues, for example, how to improve the available group programmes or how to access to mental healthcare in the neighbourhood.

\section{Sample and procedure}

Because the study encompassed the entire neighbourhood that was involved in the project, the sample was drawn from the entire population of people living, working or having a friend or relative in the neighbourhood. The broad nature of the sampling made it difficult, however, to construct a pool of potential participants from which to draw a random sample. Additionally, some people who were involved with the neighbourhood were more likely to have information that was valuable for the study than were others. A social worker, for example, was more likely to have insight into how mental healthcare functioned in the neighbourhood than was a resident who did not have someone with mental-health problems in their social network. In view of these difficulties, a systematic sampling procedure was used to sample participants with selected roles within the neighbourhood, such as general practitioners, social workers, housing managers, members of the local authority, people receiving mental healthcare, friends and relatives of people receiving mental healthcare, mental health providers, police officers and volunteers from the local community centres. The researchers approached potential participants either face-to-face or by telephone.

\section{Data collection}

Three focus group interviews were arranged, with 12 participants invited to each group interview. Participants with different backgrounds were included in each of the three focus group interviews, so that participants could react to each other, with the aim of capturing as much 


\begin{tabular}{ll}
\hline Table 1 Topic list \\
\hline 1 & $\begin{array}{l}\text { Topic } \\
\text { The collaboration between the residents living in the } \\
\text { neighbourhood. }\end{array}$ \\
$2 \quad \begin{array}{l}\text { Direction and responsibility of the residents living in the } \\
\text { neighbourhood for their mental health. }\end{array}$ \\
$3 \quad \begin{array}{l}\text { The involvement of the social network of the residents } \\
\text { living in the neighbourhood. }\end{array}$ \\
$4 \quad \begin{array}{l}\text { Whether it is difficult to arrange more or less intensive } \\
\text { care. }\end{array}$ \\
$\begin{array}{l}\text { The effect of RFCMH on the involvement of the } \\
\text { residents living in the neighbourhood. }\end{array}$ \\
$6 \quad \begin{array}{l}\text { Suggestions for improvement in the daily practice of } \\
\text { RFCMH. }\end{array}$ \\
$\begin{array}{l}\text { Whether care is aimed at personal recovery, as } \\
\text { described by the CHIME-D framework. }\end{array}$
\end{tabular}

RFCMH, Recovery Focused Community Mental Healthcare.

knowledge as possible. Authors TB (male, advanced practice nurse, PhD candidate) and RW (male, healthcare policy advisor, MS) conducted the focus group interviews. In order to reduce potential bias, two researchers with differing views on the topic of the interviews were selected for conducting the focus group interviews. RW is enthusiastic about RFCMH, whereas TB is more sceptical about the benefits of RFCMH. He is of the opinion that RFCMH has interesting and potentially beneficial components, but he views the overarching model as being overrated. Both of the interviewers were experienced at conducting focus group interviews, and neither of them was involved in the execution of the RFCMH project. The participants were not acquainted with the interviewers prior to the focus group interview. The focus group interviews were conducted in a local primary healthcare centre, which was considered neutral ground for all of the participants. Only the participants and the researchers were present at the interviews. A topic list was used to guide the focus group interviews (see table 1). Audio recordings were made of the focus group interviews using professional audio equipment. An independent assistant transcribed the recordings.

\section{Analysis}

Two of the researchers, LJv-T and TB, performed the analyses and reported the results. In order to eliminate potential bias, two researchers with prior experience with this type of research ${ }^{34}$ and with differing views of the topic were selected. LJv-T (female, advanced practice nurse, MS) is enthusiastic about RFCMH and thinks it is the way of the future in mental healthcare, whereas TB is more critical of RFCMH as a model of care.

A thematic analysis is appropriate to use in applied, exploratory research like the present study. In this study, an inductive content analysis was used. ${ }^{35}{ }^{36}$ In the first stage, two researchers independently coded all of the transcripts. Each researcher checked the other researcher's coding, and when differences occurred, they were discussed until a consensus was reached. In the subsequent stages, the codes were refined (double codes were removed, spelling errors were corrected); themes and subthemes were identified and quotations were selected to illustrate the themes and subthemes. In the final stage, a subset of participants was selected $(n=6)$ for the purpose of validating the results of the study (member check).

\section{Patient and public involvement}

Two patients were members of the committee that managed the project and initiated the study, including identifying the aims and scope of the study. In three presentations, each at a different location, the researchers informed all of the interested parties (including both the committee and the participants) of the results of the study.

\section{Ethical considerations}

Formal ethical review was not required for this study according to the guidelines of the Dutch Medical Research Involving Human Subjects Act (WMO) for the following reasons: Most of the participants did not receive mental healthcare vis-à-vis this study, the treatment of the people who did receive healthcare was not altered and data collection consisted of a single interview. Approval by the scientific board of the mental health service involved in the study was considered sufficient ${ }^{37}$ and this approval was procured. The research was performed in accordance with relevant guidelines and regulations. All participants in this study gave written informed consent prior to their participation.

\section{RESULTS}

An average of eight people (range: 6 to 10 ) participated in the focus groups, resulting in a total of 24 participants. Not all participants were willing to provide personal details, but from those who did, we were able to establish that a satisfactory balance was achieved in participants' age, sex, connection to the RFCMH project and their role within the project (see table 2). All focus group interviews lasted between 1.5 and 2 hours. The third and final focus group interview led to few new insights, which suggested that data saturation had been achieved.

Five major themes were identified, and within each theme there were two to four subthemes. These themes are project, obstacles, resident, neighbourhood and future plans (see figure 1). Each of the themes and subthemes is now discussed in succession, from the most important to the least important. Quotations from the focus group interviews are included to illustrate the contents of each theme or subtheme. For each quotation, the participant's background and focus group interview from which the quotation is taken (designated, for example, as FG1 for the first focus group interview) are reported. 


\begin{tabular}{|c|c|c|}
\hline Characteristic & Type & Data \\
\hline \multirow[t]{3}{*}{ Sex } & Male & $12(50 \%)$ \\
\hline & Female & $8(33 \%)$ \\
\hline & Rather not say & $4(17 \%)$ \\
\hline Age & & Mean 46.1, SD 11.4, $n=20$ \\
\hline \multirow[t]{4}{*}{$\begin{array}{l}\text { Connection to } \\
\text { RFCMH }\end{array}$} & $\begin{array}{l}\text { Lives in } \\
\text { neigbourhood }\end{array}$ & $12(50 \%)$ \\
\hline & $\begin{array}{l}\text { Works in } \\
\text { neighbourhood }\end{array}$ & 7 (29\%) \\
\hline & Other & $4(17 \%)$ \\
\hline & Rather not say & $1(4 \%)$ \\
\hline \multirow[t]{5}{*}{$\begin{array}{l}\text { Role within } \\
\text { RFCMH }\end{array}$} & $\begin{array}{l}\text { (Mental) } \\
\text { healthcare } \\
\text { practitioner }\end{array}$ & $9(37 \%)$ \\
\hline & Received care & $4(17 \%)$ \\
\hline & $\begin{array}{l}\text { Significant other } \\
\text { of someone } \\
\text { receiving care }\end{array}$ & $4(17 \%)$ \\
\hline & $\begin{array}{l}\text { Inhabitant of the } \\
\text { neighbourhood } \\
\text { (not one of the } \\
\text { above) }\end{array}$ & $4(17 \%)$ \\
\hline & Rather not say & $3(13 \%)$ \\
\hline
\end{tabular}

RFCMH, Recovery Focused Community Mental Healthcare.

\section{Project}

Project is the first theme, and it comprises four subthemes. The subtheme that was most often discussed was peer workers and their role in the RFCMH project, which on the whole was judged as positive. Both the service users and the healthcare providers praised the peer workers for being easily accessible. Everyone involved viewed their approach to care favourably, especially when (a) it focussed on personal recovery (for example, when it aimed to empower service users or to improve their social roles) and (b) it offered pragmatic solutions before the severity of the mental health problems escalated to a level that required specialist mental healthcare. When specialist mental healthcare was still needed, the peer workers were applauded for arranging a referral to appropriate care, while also aiming to meet the expectations of service users and their friends and relatives. General practitioners in particular respected the skills of the peer workers in their dealing with all types of service users, even the most demanding ones. Similarly, the service users applauded the lack of professional distance between the healthcare providers and themselves, and they described this as facilitating a better relationship. In all of the focus group interviews, the deployment of peer workers was described as a successful component of RFCMH.

Service user (FG2): When you hear that you will have a session with a peer worker, that feels totally different than a session with a regular healthcare provider. Reply by significant other: Peer workers are just easier to approach.

General practitioner (FG1): What I would like is 10 peer workers instead of the mental health nurses. They just get so much more done.

Another frequently discussed topic was access to care. The discussions focussed on the importance of not referring service users to specialist mental healthcare when it was not really needed, but being able to easily and quickly refer them to appropriate care when it was needed. A special role was attributed to the peer workers. They were viewed as having a low threshold for becoming involved and providing the care themselves when it was sufficient, but they assisted with an appropriate referral when one was needed. On the other hand, the community residents noted that although the peer workers and the healthcare providers visited their neighbourhood, additional outreach was needed, for example in the locales where the residents met.

Service user (FG2): You need someone who searches with you for a solution to your problem.

Peer worker (FG1): That is the other solution, specialist mental health care for those who really need it.

General practitioner (FG1): That (involving peer workers) really helps, it lowers the threshold.

A third subtheme was the cooperation of the healthcare workers. There was a clear consensus that the cooperation
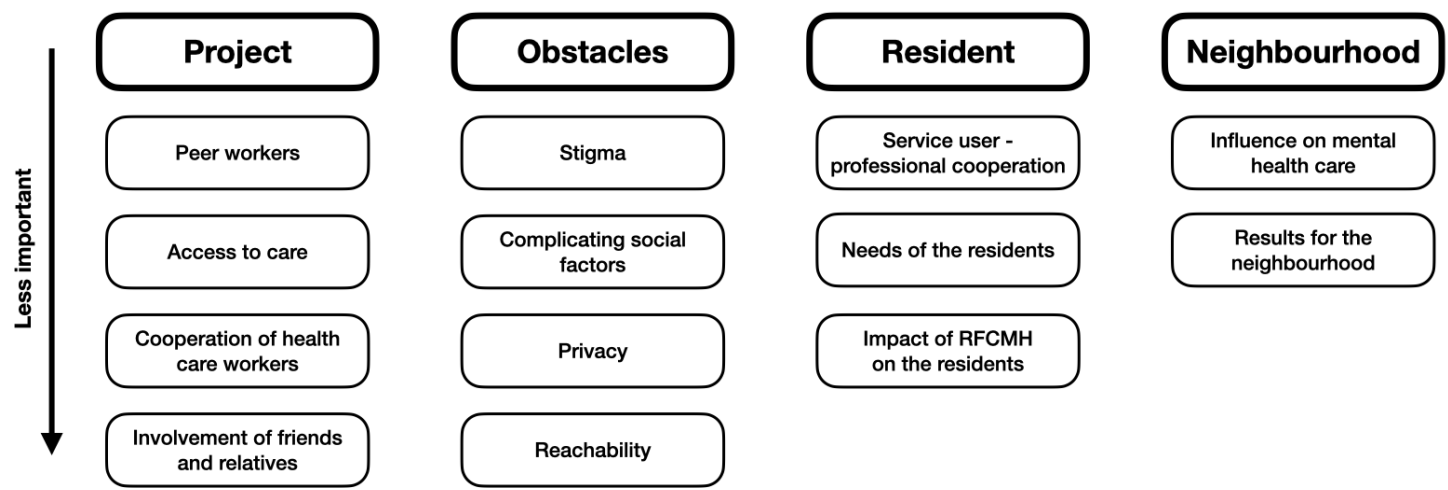

Future plans

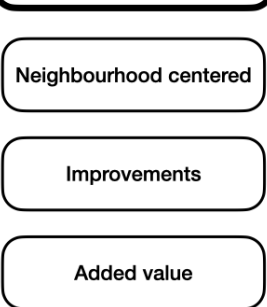

Transparency

Figure 1 Themes and subthemes. RFCMH, Recovery Focused Community Mental Healthcare. 
of all of the healthcare workers who were involved in service users' care was needed. However, there was a lack of consensus on how the cooperation could be best implemented and communicated. One component of RFCMH was a weekly meeting for all of the healthcare workers who were involved. At the meeting, the healthcare workers could discuss the service users' needs and how they could best be helped, especially with regard to topics that were recurring. Most of the participants indicated that they did not experience this meeting positively. A problem that was frequently mentioned was that often not all of the healthcare providers whose presence was needed were at the meetings. Also, the dominant perspective that was voiced at the meetings was that of the mental health providers, even though the aim of RFCMH was to focus on the service users' personal recovery. Additionally, concerns were raised about privacy, as discussed under the theme obstacles. The healthcare providers preferred to have informal communications in the language of the service users, yet no clear guidelines were discussed about how to improve the communication.

Peer worker (FG1): It is remarkable that the mental health perspective prevails, while there are so many other perspectives.

Psychiatrist (FG2): I think the improved communication is positive, but we continue to miss a large part of what is important in the care for these people (the residents).

General practitioner (FG1): The informal communication between healthcare providers is a good thing.

One additional subtheme was briefly discussed. The involvement of friends and relatives in the care of service users was deemed important, but there was not much in-depth discussion of this topic, aside from the view that the friends and relatives of all of the service users should be involved.

\section{Obstacles}

The theme obstacles also had four subthemes. The subtheme that was discussed most frequently and at greatest length was stigma. Although there was consensus that easy access to adequate mental healthcare is essential, mental health problems still have many negative connotations, which increase the threshold required to seek help.

Healthcare provider (FG2): When we organise a public information session at the meeting place (on the subject of mental healthcare), the place is full of interested residents, but nobody present has a mental health problem or knows someone who does. Response from a general practitioner: I think, and this is also what I hear tonight, that there is still a taboo about having a psychiatric illness.

Another aspect of the stigma that was discussed was whether 'mental health' should be a part of the project's title, because this term invokes stigma generally and self-stigma specifically. On the other hand, if the term mental health were not used, the aim of the project would not be obvious. This dilemma was discussed in all of the focus group interviews, but it was solved in none of them.

Service user (FG1): That name (mental healthcare), that is where the stigma starts. Response by a psychiatrist: But it is mental healthcare, I am a medical professional and it is paid as mental healthcare. Reply by healthcare provider: It is a good thing that (the mental health service) took the initiative to start RFCMH, but it should not be called mental healthcare. It discourages people to seek help.

Resident (FG1): Involving someone (in a meeting place) without identifying her as a mental health provider would be a dirty trick!

There also was ample discussion on the subtheme complicating social factors, which encompasses social factors that can compromise one's mental health and the ability to seek help from mental healthcare providers. These factors include poverty, paid work, cultural background, illiteracy and the financial cost of care. These five subthemes underscore participants' concern that healthcare providers should regard these factors as ones that could potentially negatively affect the care that service users receive. Illiteracy in particular was named as a complicating factor in residents' seeking the care they need. It, therefore, strengthens the barrier for accessing care, both mental healthcare and other kinds of care.

Resident (FG2): There are a lot of invitations on the wall at the meeting centre, but if you can't read them, you can't benefit from them.

Social worker (FG2): There was a woman that frequented the meeting place and received a lot of support there, but when her husband found out there were also men there, she was no longer allowed to come.

General practitioner (FG2): Some people just can't afford (financially) to ask for help.

The subtheme privacy is yet another obstacle in RFCMH. Close and open communication among healthcare providers is a key component of RFCMH, but it is at odds with privacy laws in the Netherlands, as it would probably be in most other Western countries. Consultation is allowed only after written consent is obtained, but procuring written consent for consultation with the variety of different healthcare providers is time-consuming and difficult to achieve. A substantial proportion of the service users are hesitant to sign what they perceive to be a blank check. So far, there has been no satisfactory solution to this problem.

Service user (FG1): That (consultation) can be dangerous. You don't know what has been discussed.

The last subtheme under the theme obstacles is reachability, which is another difficulty for RFCMH. Service 
users, their friends and relatives and the community residents explained that their needs for care or assistance are not confined to business hours. Healthcare providers, however, are usually unreachable outside of normal business hours. This leads to feelings among the service users and their friends and relatives of being let down by the healthcare providers. The peer workers are an exception, in that some of them are available via their mobile phones outside of normal office hours. The peer workers indicated that there had been little use or abuse of this practice, but that the possibility of being able to reach a peer worker results in lower stress levels among both the service users and their friends and relatives, and it also reduces the need to actually call the peer worker. Other aspects of availability are the ease with which healthcare providers can reach one another and how easy it is for residents to find a healthcare provider when one is needed.

Service user (FG1): The hardest moments of my life always seem to occur outside of office hours. I need my healthcare provider then but she cannot be reached! Psychiatrist: I don't think we should be reachable outside of office hours. If service users need help at night, they should contact crisis management services. Response from peer worker: I disagree. They (service users) hardly ever call outside of office hours and when they do, they really need my help, and that is fine. Response from another peer worker: When they (service users) call outside of office hours they are in a really bad place and need a sympathetic ear. They don't call for problems with their landlord or something like that. Reply by healthcare provider: People have to be able to find you!

\section{Residents}

The theme residents has three subthemes. As its name implies, the theme cooperation between service user and healthcare provider is related to how service users and healthcare providers cooperate with one another. On the one hand, it is about how service users can make their own choices, especially in the healthcare they receive. On the other hand, it is related to conversations about how much psychological distance healthcare providers should create between themselves and service users (professional distance). Participants reported that healthcare practitioners, especially the peer workers, kept little psychological distance between themselves and the service users.

Peer worker (FG1): We often ask the question, what does the service user want?

Service user (FG1): ...I noticed that (name), who is a psychiatrist at RFCMH, contacts us as a family and as a fellow human being, for example by visiting us at home.

Another subtheme under the theme residents is needs of the residents. This is a major subtheme, which deals mostly with individual residents' unmet needs. Examples of the needs that were mentioned include: more options in the care that residents receive, lower thresholds to gain access to care, the personal attention that healthcare workers provide, more practical support with work-related and financial problems, actively involving friends and relatives in residents' care, improving residents' social network and availability of healthcare providers from the same ethnic background as the service users.

Service user (FG3)(on the question of whether friends and relatives were involved in the care): Earlier, when I received care, I did so alone. Now my family has become involved and can support me.

Peer worker (FG1): I met a service user last week who insisted on receiving care from a health care provider from the same ethnic background.

The last subtheme under residents is the impact of RFCMH on the residents. The overall conclusion of all of the participants was that it was too early to draw conclusions about the effects of RFCMH on the health of the residents.

Healthcare provider (FG3): That (the effect of RFCMH on the health of the residents) is not yet clear. Response from another healthcare provider: That is what I mean, the gains for the residents still have to be shown.

\section{Neighbourhood}

The fourth theme is neighbourhood, which has two subthemes. The subtheme influence on mental healthcare is related to how residents in the neighbourhood (especially key figures) can influence how mental healthcare in the neighbourhood is organised. Topics discussed in the focus groups that were related to the neighbourhood included involvement in existing projects in the community, a low threshold for care and how healthcare providers should be available in the neighbourhood meeting places.

Resident (FG2): We have to make mental healthcare easily available for the residents, as, for example, in the meeting place next door to my house.

General practitioner (FG1): I think mental healthcare providers should be aware there is more than treatment by psychologists and psychiatrists, for example, other projects to promote healthcare, both from healthcare providers and volunteer organisations, like the meeting places in the neighbourhood and the peer workers.

Service user (FG3): I don't know what to do. I need contact with other people, but I don't know where to go.

The last subtheme under the main theme neighbourhood is results for the neighbourhood. It is concerned with whether RFCMH has had an effect on the topics identified in the other subthemes under the main theme neighbourhood. The conclusion from discussions in all of the focus-group interviews was that there had been few or no noticeable changes since RFCMH started a year earlier. 
Service user (FG3): I noticed nothing.

Resident (FG2): The meeting place is open every day. Help us improve it. Show yourselves (mental healthcare providers) at the meeting place. That is where the people who need you are!

\section{Future plans}

The last theme is future plans, which includes four subthemes. It mainly discusses how to further improve RFCMH.

The most discussed subtheme was neighbourhood-centred. All participants agreed that the focus of RFCMH should be on supporting existing initiatives in the neighbourhood instead of starting new ones. There was also some discussion on the extent in which RFCMH succeeded in supporting existing initiatives, but most of the discussion was centred on how to support existing initiatives in this specific neighbourhood.

Resident (FG2): We (organisers of a meeting place) notice little about RFCMH in our meeting place. Response by healthcare provider: There are a lot of good initiatives organised by residents, but I am just not acquainted with a lot of them. I really could use a guide to all the available initiatives.

Another subtheme is called improvements. The participants indicted that most of the efforts of RFCMH were aimed at people who had already experienced some mental health problems, and that hardly any resources were allocated to prevention. Organising self-help groups would be one way to focus more on prevention. In a selfhelp group, people could acquire skills for being better prepared to handle problems in their lives before they lead to mental health issues.

Significant other (FG3): Don't wait with mental healthcare until people fall apart. Most people postpone getting mental healthcare until they fall apart, but it should be easier for people to get help before they reach that point.

Peer worker (FG2): There are plans to organise selfhelp groups, and we have contacted people who have organised them before, but we should really speed up the process.

Participants also discussed whether several aspects of RFCMH actually had added value. The main conclusion was that most of the care that is provided is care as usual, but aspects of it do have added value. One example of this added value is the deployment of peer workers. Another example of added value is that the threshold for starting mental healthcare is considerably lower in RFCMH than with regular mental health services, both for the service users and for other healthcare providers.

General practitioner (FG1): The threshold for referring to the psychiatrists in RFCMH is a lot lower (than with regular mental health services). Response by psychiatrist: Each month, I visit three general practitioners' offices to collaborate on service user care, and this is greatly appreciated.

The service users and the residents were the main ones to identify the subtheme transparency. They viewed mental healthcare as an incomprehensible black box. They described situations in which they had little insight into the workings of mental healthcare, and they feared that care providers might go behind their backs in order to reach their own goals. Not all service users and residents shared this view about mental healthcare, but in all three of the focus groups, transparency was mentioned, so it cannot be ignored in further developments of RFCMH.

Resident (FG2): People (mental healthcare providers) join conversations in the meeting place without disclosing their role as a mental healthcare provider in the meeting place! Service user (FG2): And they (mental healthcare providers) talk about you behind your back.

\section{DISCUSSION}

The participants in the focus group interviews considered RFCMH as a whole to have made little contribution to the mental health of the residents living in the neighbourhood, although certain elements of RFCMH were reported to have made a positive contribution. Thus, instead of assessing the contribution of RFCMH on the mental health of the residents living in the neighbourhood as a whole, it is more fruitful to consider how the individual RFCMH interventions contributed to the residents' mental health. Interventions that were judged to have made a clearly positive contribution to the mental health of the residents are those that involved peer workers and the ones that aimed to improve collaboration among the healthcare providers. An intervention that did not meet these expectations was the weekly meetings of the healthcare providers. Connecting with the existing initiatives in the neighbourhood is an intervention that was viewed as having much potential, but which proved to be more difficult to achieve than had been expected.

Including peer workers in a mental health team was viewed as advantageous. ${ }^{38} 39$ Peer workers, for example, could help to shift the focus of care away from reducing symptoms and risks and towards personal recovery. ${ }^{40}$ Care provided by peer workers was expected to have a positive impact on service users' symptomatology, social support, hope and empowerment. ${ }^{4142}$ These previously discussed advantages of peer workers are reflected in the current study, for instance in the quotations from general practitioners and other healthcare providers that praise the efforts of the peer workers and the results they helped to achieve in RFCMH.

The successful usage of peer workers in mental healthcare cannot be taken for granted. Simply adding peer workers to a mental health team does not in itself shift the focus to personal recovery, nor does it not guarantee 
that collaborations will be successful. ${ }^{40-45}$ Concerted efforts must be made to successfully collaborate with peer workers. ${ }^{46}{ }^{47}$ In the case of RFCMH, these efforts amount to creating a role for the peer workers in which healthcare providers respect their skills, and the peer workers are facilitated in performing the work they are intended to do. When placed in a nurturing position like that described here, peer workers can do what they do best: work together with service users and their friends and relatives and with healthcare providers to improve the service users' personal recovery.

The weekly project meetings did not live up to the expectation that they would improve collaboration among the healthcare providers. In fact, a considerable number of the healthcare providers expressed their frustrations with the weekly project meetings. Additionally, most of the healthcare providers judged the project meetings as inefficient or not worth the effort required for small gains to be achieved. Adhering to the existing privacy laws was yet another problem with the weekly project meetings. It is, nevertheless, essential that projects like RFCMH have an effective forum in which healthcare providers and peer workers from different background can improve collaboration among the different healthcare providers. ${ }^{30} 47-49$ Based on the focus-group interviews, we can conclude that the project succeeded in improving cooperation among the healthcare providers. In fact, there were several factors that helped to improve the cooperation. When an effort is being made to improve collaboration among healthcare providers, it is important for the providers to know each other and to be able to communicate with one another without using technical jargon that the other providers might not understand. ${ }^{50-53}$ Another important consideration is that the different kinds of healthcare providers should be available for one another when they are needed, and it is important for them to want to make an effort to help one another. ${ }^{545}$

Participants from all backgrounds deemed it important to connect with the existing initiatives in the neighbourhood. The participants in this study also viewed outreach as necessary for reaching out to those residents with the highest threshold for asking for help in order to improve their mental health. In this project, the outreach provided in the neighbourhood was judged to be inadequate. Although the healthcare providers involved in the project were seen as making an effort to do their best, most of the residents who participated in the focus group interviews had not interacted with the RFCMH healthcare providers. It is, of course, important but often difficult to reach every individual who might need mental healthcare, especially those who have a high threshold for asking for help. ${ }^{567}$ There are no universal solutions for improving outreach and connecting with all residents in all situations, but an increasing number of studies, including the RFCMH project, are providing potential solutions.$^{58-60}$

As a result of the present study, the RFCMH project has evolved into a new phase. The deployment of peer workers has, for example, been intensified. Three modifications were made in the weekly meetings, which were aimed at improving collaboration: (a) the frequency of the meetings was reduced to one meeting every 2 weeks, (b) a chair was appointed to preside at the meetings and (c) the meetings are now focussed more on individual service users and their needs. At the same time, the views of all of the participants at the meetings are respected, but discussion at the meetings of participants' divergent views are avoided. Outreach in the community has been improved by fostering additional collaboration with the informal community leaders. This includes, for example, the people who manage small projects in the neighbourhood. How to collaborate efficiently on the level of service users while adhering to the requirements of privacy laws is an ongoing issue. The healthcare providers are, nevertheless, making this work in their daily practice.

\section{STRENGTHS AND LIMITATIONS}

This study had a number of strengths, especially its thorough design. Other examples include an adequate number of participants, sampling from a broad range of participants, and the analysis that included independent coding by two different researchers. Another strength is the saturation in the themes that were discussed. This occurred in the third focus group interview, and it resulted in exhaustive data collection. The major weakness of this study is that it provided only a snapshot of the local situation, which therefore reduces the study's generalisability. Despite this weakness, lessons can be learned from this project for implementing similar projects in different locales. Although it might be impeded by the large sample that is needed, future research should include a quantitative evaluation of RFCMH, both from the perspective of the service user and at the neighbourhood level.

Another weakness of this study is its focus group design. For example, participants in a focus group might be reluctant to discuss delicate issues because of the presence of other participants. This might be especially true in a focus group in which there are participants from different backgrounds (as there was in this study), for fear of negative reactions. Another potential limitation of focus group interviews, which also applies to the current study, is that participants might give the answers they think the researchers want to hear (ie, there might be a social desirability bias), and participants might unwittingly engage in conversational patterns that encourage or discourage specific reactions from the other participants.

\section{CONCLUSION}

In conclusion, the RFCMH project as a whole does not provide a panacea for recovery-oriented community mental healthcare. It does, however, have a variety of strong components, which offer ways to improve the mental health of the community residents and which orient mental healthcare towards personal recovery. 
A major feature of RFCMH is its usage of peer workers from the initiation of mental healthcare. The ability of RFCMH to improve communication among the different kinds of healthcare providers is another component that was well regarded. On the other hand, although facilitating connections with existing initiatives in the neighbourhood was considered important, it proved difficult to achieve.

\section{Twitter Thijs Beckers @thijsbeckers}

Contributors TB: study design, data collection, data analysis, reporting the results. LJV-T: study design, data collection, data analysis, reporting the results. RW: study design, data collection, reporting the results. MK: study design, reporting the results. DC: study design, reporting the results.

Funding The participating mental health services funded the project, but none of them was involved in data collection, analysis or reporting.

Competing interests All authors reported that they have no conflict of interest.

Patient consent for publication Not required.

Provenance and peer review Not commissioned; externally peer reviewed.

Data availability statement Data are available upon reasonable request. To preserve confidentiality, the data collected during the course of this study will not be publicly shared. Statements made by individual participants in the specific neighbourhood would make it easy to know the identity of the participants. However, the data (in Dutch) will be made available to individual researchers if they contact the corresponding author.

Open access This is an open access article distributed in accordance with the Creative Commons Attribution Non Commercial (CC BY-NC 4.0) license, which permits others to distribute, remix, adapt, build upon this work non-commercially, and license their derivative works on different terms, provided the original work is properly cited, appropriate credit is given, any changes made indicated, and the use is non-commercial. See: http://creativecommons.org/licenses/by-nc/4.0/.

\section{ORCID iD}

Thijs Beckers http://orcid.org/0000-0003-1557-5387

\section{REFERENCES}

1 van der Lee A, de Haan L, Beekman A. Schizophrenia in the Netherlands: continuity of care with better quality of care for less medical costs. PLoS One 2016;11:e0157150.

2 Westra D, Wilbers G, Angeli F. Stuck in the middle?: a perspective on ongoing pro-competitive reforms in Dutch mental health care. Health Policy 2016:120:345-9.

3 van Mens K, Lokkerbol J, Janssen R, et al. A cost-effectiveness analysis to evaluate a system change in mental healthcare in the Netherlands for patients with depression or anxiety. Adm Policy Ment Health 2018;45:530-7.

4 Kataria D, Jiloha RC, Bhatia MS, et al. A study of treatment-seeking behavior in psychiatric patients at a tertiary care hospital in Delhi. $J$ Mental Health Hum Behav 2018;23:33-7.

5 Henderson C, Evans-Lacko S, Thornicroft G, et al. Help seeking, and public health programs. Am J Public Health 2013;103:777-80.

6 Gulliver A, Griffiths KM, Christensen H. Perceived barriers and facilitators to mental health help-seeking in young people: a systematic review. BMC Psychiatry 2010;10:113.

7 Corrigan PW, Druss BG, Perlick DA. The impact of mental illness stigma on seeking and participating in mental health care. Psychol Sci Public Interest 2014;15:37-70.

8 Jones E, Lebrun-Harris LA, Sripipatana A, et al. Access to mental health services among patients at health centers and factors associated with unmet needs. J Health Care Poor Underserved 2014;25:425-36.

9 Mojtabai R, Olfson M, Sampson NA, et al. Barriers to mental health treatment: results from the National comorbidity survey replication. Psychol Med 2011;41:1751-61.

10 Thornicroft G, Mehta N, Clement S, et al. Review evidence for effective interventions to reduce mental-health-related stigma and discrimination. The Lancet 2015;207:377-84.

11 Kazdin AE, Rabbitt SM. Novel models for delivering mental health services and reducing the burdens of mental illness. Clin Psychol Sci 2013;1:170-91.
12 Andrews G, Issakidis C, Carter G. Shortfall in mental health service utilisation. Br J Psychiatry 2001;179:417-25.

13 Clement S, Schauman O, Graham T, et al. What is the impact of mental health-related stigma on help-seeking? A systematic review of quantitative and qualitative studies. Psychol Med 2015;45:11-27.

14 World Health Organization. Mental health financing: mental health policy and service guidance package. Geneva: World Health Organisation, 2003.

15 Corrigan PW, Watson AC. Factors that explain how policy makers distribute resources to mental health services. Psychiatr Serv 2003;54:501-7.

16 Davies M. Allocating resources in mental health: a clinician's guide to involvement. Adv. psychiatr. treat 2006;12:384-91.

17 Hensen MJ, de Mooij LD, Theunissen J, et al. Pathways through care of severely mentally ill individuals experiencing multiple public crisis events: a qualitative description. BMC Psychiatry 2016;16:1-10.

18 Tinelli M, Kanavos P. Cost and impact of non-treating severe mental illnesses (SMIs): the case study of schizophrenia. London: London School of Economics and Political Science, 2015.

19 Beckers T, Koekkoek B, Hutschemaekers G, et al. Potential predictive factors for successful referral from specialist mental-health services to less intensive treatment: a concept mapping study. PLoS One 2018;13:e0199668.

20 Anthony WA. Recovery from mental illness: the guiding vision of the mental health service system in the 1990s. Psychosocial Rehabilitation Journal 1993;16:11-23.

21 Shanks V, Williams J, Leamy M, et al. Measures of personal recovery: a systematic review. Psychiatr Serv 2013;64:974-80.

22 Leamy M, Bird V, Le Boutillier C, et al. Conceptual framework for personal recovery in mental health: systematic review and narrative synthesis. Br J Psychiatry 2011;199:445-52.

23 van Os J, Guloksuz S, Vijn TW, et al. The evidence-based group-level symptom-reduction model as the organizing principle for mental health care: time for change? World Psychiatry 2019;18:88-96.

24 O'Brien BC, Harris IB, Beckman TJ, et al. Standards for reporting qualitative research: a synthesis of recommendations. Acad Med 2014;89:1245-51.

25 Roermond Atlas. Welkom bij de Roermond atlas. Available: http:// www.roermondatlas.nl [Accessed Jan 2020].

26 Statistics Netherlands. Figures about Society. Available: https://www. cbs.nl/en-gb/society [Accessed Jan 2020].

27 Slade M, Longden E. Empirical evidence about recovery and mental health. BMC Psychiatry 2015;15:285.

28 Vandewalle J, Debyser B, Beeckman D, et al. Peer workers' perceptions and experiences of barriers to implementation of peer worker roles in mental health services: a literature review. Int J Nurs Stud 2016;60:234-50.

29 Christensen RC. Psychiatric street outreach to homeless people: fostering relationship, reconnection, and recovery. $J$ Health Care Poor Underserved 2009;20:1036-40.

30 Olivet J, Bassuk E, Elstad E, et al. Outreach and engagement in homeless services: a review of the literature. Health Policy 2010;3:53-70.

31 Fleury M-J, Imboua A, Aubé D, et al. Collaboration between general practitioners (GPs) and mental healthcare professionals within the context of reforms in Quebec. Ment Health Fam Med 2012;9:77-90.

32 Mosadeghrad AM. Factors influencing healthcare service quality. Int $J$ Health Policy Manag 2014;3:77-89.

33 Long JC, Cunningham FC, Braithwaite J. Bridges, brokers and boundary spanners in collaborative networks: a systematic review. BMC Health Serv Res 2013;13:158.

34 Beckers T, Koekkoek B, Tiemens B, et al. Substituting specialist care for patients with severe mental illness with primary health care. experiences in a mixed methods study. J Psychiatr Ment Health Nurs 2018;58:1219.

35 Elo S, Kyngäs $\mathrm{H}$. The qualitative content analysis process. J Adv Nurs 2008;62:107-15.

36 Hsieh H-F, Shannon SE. Three approaches to qualitative content analysis. Qual Health Res 2005;15:1277-88.

37 Central Committee on research involving human subjects. Your research: is it subject to the WMO or not? 2019. Available: https:// english.ccmo.nl/investigators/legal-framework-for-medical-scientificresearch/your-research-is-it-subject-to-the-wmo-or-not

38 Davidson L, Bellamy C, Guy K, et al. Peer support among persons with severe mental illnesses: a review of evidence and experience. World Psychiatry 2012;11:123-8.

39 Pitt V, Lowe D, Hill S, et al. Consumer-providers of care for adult clients of statutory mental health services. Cochrane Database Syst Rev 2013;67:491. 
40 Slade M, Amering M, Farkas M, et al. Uses and abuses of recovery: implementing recovery-oriented practices in mental health systems. World Psychiatry 2014;13:12-20.

41 Repper J, Carter T. A review of the literature on peer support in mental health services. J Ment Health 2011;20:392-411.

42 Cabassa LJ, Camacho D, Vélez-Grau CM, et al. Peer-based health interventions for people with serious mental illness: a systematic literature review. J Psychiatr Res 2017;84:80-9.

43 Moran GS, Russinova Z, Gidugu V, et al. Challenges experienced by paid peer providers in mental health recovery: a qualitative study. Community Ment Health J 2013;49:281-91.

44 Kemp V, Henderson AR. Challenges faced by mental health peer support workers: peer support from the peer supporter's point of view. Psychiatr Rehabil J 2012;35:337-40.

45 Mark C, Varker T, Visson J, et al. Guidelines for peer support in high-risk organizations: an international consensus study using the Delphi method Journal of traumatic stress. J.Traumatic Stress 2012;25:134-41.

46 Myrick K, Del Vecchio P. Peer support services in the behavioral healthcare workforce: state of the field. Psychiatr Rehabil J 2016;39:197-203.

47 Gillard S, Gibson SL, Holley J, et al. Developing a change model for peer worker interventions in mental health services: a qualitative research study. Epidemiol Psychiatr Sci 2015;24:435-45.

48 Zwarenstein M, Goldman J, Reeves S. Interprofessional collaboration: effects of practice-based interventions on professional practice and health care outcomes. CDSR 2009;42:779.

49 Reeves S, Pelone F, Harrison R, et al. Interprofessional collaboration to improve professional practice and health care outcomes. Cochrane Database Syst Rev 2017;19.
50 Fredheim T, Danbolt LJ, Haavet OR, et al. Collaboration between general practitioners and mental health care professionals: a qualitative study. Int J Ment Health Syst 2011;5:13.

51 Fewster-Thuente L, Velsor-Friedrich B. Interdisciplinary collaboration for healthcare professionals. Nurs Adm Q 2008;32:40-8.

52 Schoop M. An empirical study of multidisciplinary communication in health care using a language-action perspective. LAP 1999:59-72.

53 Martin JS, Ummenhofer W, Manser T, et al. Interprofessional collaboration among nurses and physicians: making a difference in patient outcome. Swiss Med Wkly 2010;140:w13062.

54 Gittell JH, Godfrey M, Thistlethwaite J. Interprofessional collaborative practice and relational coordination: improving healthcare through relationships. J Interprof Care 2013;27:210-3.

55 Cunningham FC, Ranmuthugala G, Plumb J, et al. Health professional networks as a vector for improving healthcare quality and safety: a systematic review. BMJ Qual Saf 2012;21:239-49.

56 Kataoka SH, ljadi-Maghsoodi R, Figueroa C, et al. Stakeholder perspectives on the social determinants of mental health in community coalitions. Ethn Dis 2018;28:389-96.

57 Campbell T, Goodrich R, Inclusion P. Equity and deliberation in a national dialogue on mental health. JPD 2016;12:8.

58 Dickson-Gomez J, Quinn K, Bendixen A, et al. Identifying variability in permanent supportive housing: a comparative effectiveness approach to measuring health outcomes. Am J Orthopsychiatry 2017;87:414-24.

59 Houle J, Coulombe S, Radziszewski S, et al. An intervention strategy for improving residential environment and positive mental health among public housing tenants: rationale, design and methods of flash on my neighborhood! BMC Public Health 2017;17:737.

60 Castillo EG, Chung B, Bromley E, et al. Community, public policy, and recovery from mental illness. Harv Rev Psychiatry 2018:1-22. 